\title{
Níveis Comparativos de Estresse Oxidativo em Camundongos em Duas Situações do Limite Orgânico: Overreaching Induzido por Treinamento de Natação e Câncer
}

\author{
Comparative Oxidative Stress Levels in Mice Submitted to Two Situations \\ of Organic Limit: Overreaching Induced by Swimming Training and Cancer
}

Joaquim Maria Ferreira Antunes Neto Rodrigo José Battibugli Rivera'

Régis Georgis Calvi'

Maryellen Fernandes Raffa'

Caio César Donadon

Angélica Gomes Pereira'

Patrícia da Silva Melo

\section{Laboratório de Estudos}

Multidisciplinares do Estresse (LEME). Faculdades Integradas Metropolitanas de Campinas (Metrocamp), Campinas, São Paulo, Brasil.

\section{Endereço para correspondência:} Prof. Dr. Joaquim M. F. Antunes Neto Faculdades Integradas

Metropolitanas de Campinas - Metrocamp. Laboratório de Estudos Multidisciplinares do Estresse (LEME). Rua Abolição, 2.008

- 13041-443 - Campinas, SP.

E-mail:

joaquim_netho@yahoo.com.br

Submetido em 10/01/2008

Versão final recebida em 25/05/2008 Aceito em 05/07/2008

\section{RESUMO}

O objetivo deste trabalho foi comparar concentrações de estresse oxidativo em camundongos da linhagem Balb-C submetidos a duas condições severas de alterações orgânicas: treinamento exaustivo de natação (overreaching - grupo OVER; $n=10$ ) e inoculação por tumor ascítico de Ehrlich (grupo TAE; $n=10$ ). A proposta foi analisar como as duas situações comprometiam o equilíbrio entre os sistemas oxidantes e antioxidantes. Foram investigados alguns marcadores de estresse oxidativo, tais como as substâncias reativas ao ácido tiobarbitúrico (TBARS) e concentrações da atividade da enzima antioxidante catalase (CAT) no hemolisado. Como marcadores de lesão celular, quantificaram-se concentrações plasmáticas das enzimas creatina quinase (CK) e aspartato transferase (AST); complementado; também se observaram padrões de alterações fisiológicas por meio da quantificação plasmática de creatinina e uréia. Como resultados mais importantes, pôde-se observar que, nas duas situações de limite orgânico, seja por exercício exaustivo (OVER) ou pela inoculação de TAE, houve queda abrupta na concentração da enzima CAT (decréscimos de 30\%; $p<0,01$ e 72\%; $p<0,001$, respectivamente, comparando-se com o grupo treinado - T). Quanto à concentração de peroxidação lipídica (TBARS), detectaram-se aumentos significativos para os grupos OVER e TAE em relação ao grupo T (52\%, p < 0,01; 90\%, p < 0,001, respectivamente). Níveis liberados de CK foram mais proeminentes no grupo OVER, enquanto que a quantidade de AST no plasma foi mais elevada no grupo TAE. Chegou-se à conclusão de que os organismos estudados possuem um mesmo perfil de estresse oxidativo em situações limites que envolvem exercício físico e doença. Tais resultados permitirão profissionais envolvidos com elaboração das cargas de treinamento físico a se preocuparem com os períodos recuperativos, o que impede a instalação do quadro de overreaching, o qual se mostrou tão severo, em termos de estresse oxidativo, quanto o de uma situação patológica.

Palavras-chave: estresse oxidativo, overreaching, natação, tumor ascítico de Ehrlich.

\section{ABSTRACT}

The aim of this study was to compare oxidative stress levels in mice (Balb-C) submitted to two severe organic conditions: exhaustive swimming training (overreaching - OVER group; $\mathrm{n}=10$ ) and inoculation of the Ehrlich's Ascitic Tumor (EAT group; $n=10$ ). Lipid peroxidation, quantified by thiobarbituric acid reactive substances (TBARS), and levels of antioxidant enzyme (catalase- CAT) were used as indicators of oxidative stress. Muscle damage levels were measured through plasma creatine kinase (CK), aspartate transaminase (AST) as well as blood creatinine and urea activities samples. As main results, it has been observed that in both situations, whether by exhaustive exercise (OVER) or inoculation of EAT, dramatic decrease in the catalase activity levels was present when compared with the training group (T) (30\%; $p<0.01$ and 72\%; $p<0.001$, respectively) with concomitant increase in plasma TBARS concentration (52\%; $p<0.01$ and $90 \% p<0.001$, respectively). Plasma CK levels were more prominent in the OVER group, while the amount of AST plasma was higher in the EAT group. We concluded that the same profile of oxidative stress was found in situations involving exhaustive exercise and pathology. These results will allow professionals involved with load training manipulation to be concerned with the rest periods, preventing hence the installation of overreaching, which in terms of oxidative stress, was as severe as a pathological conditions.

Keywords: oxidative stress, overreaching, swimming training, Ehrlich's ascitic tumor. 


\section{INTRODUÇÃO}

Uma das possibilidades do estudo das respostas do estresse oxidativo está no monitoramento do treinamento de atletas. Como tais estudos ainda carecem de muitas respostas, as pesquisas experimentais, com utilização de animais, podem trazer informações relevantes. As espécies reativas de oxigênio (EROs), também conhecidas como radicais livres, são formadas, principalmente, pela redução incompleta do oxigênio nos processos de geração de energia. O oxigênio consumido tem como principal via de metabolismo o sistema aeróbio, ou seja, a mitocôndria ${ }^{(1)}$. Esse sistema é responsável pela utilização de 85 a 90\% de todo o oxigênio consumido, os outros 10 a 15\% sendo utilizados por enzimas oxidases e oxigenases e por reações químicas de oxidação direta. Dos 85 a 90\% de oxigênio que chegam à cadeia de transporte de elétrons, 2 a 5\% são reduzidos unilateralmente em metabólitos, tal como as EROs ${ }^{(2)}$. Durante a atividade física, o consumo de oxigênio pode aumentar até 20 vezes e sua captação pelos músculos ativos pode aumentar até 100 vezes, favorecendo, dessa maneira, a formação de $\operatorname{EROs}^{(3)}$.

O estresse oxidativo ocorre em circunstancias nas quais há desequilíbrio entre os sistemas prooxidantes e antioxidantes, de maneira que os primeiros sejam predominantes ${ }^{(2)}$. Dentro de uma estratégia de manutenção do estado redox contra condições oxidantes, o sangue exerce um papel fundamental, fazendo o transporte e redistribuição dos antioxidantes para todo o corpo; dessa maneira, a capacidade antioxidante no sangue pode nos dar estimativas dos níveis de estresse oxidativo, permitindo um modo de mensuração menos invasivo que por outras vias, como pela biópsia( ${ }^{(1)}$.

Para livrar o organismo dos efeitos deletérios das EROs, há sistemas antioxidantes divididos em duas classes: o sistema não enzimático, composto principalmente pôr $\beta$-caroteno (pró vitamina A), ácido ascórbico (vitamina C) e alfa tecoferol (vitamina E), e o sistema enzimático, com a catalase (CAT), glutationa peroxidase (GPX), glutationa redutase $(G R)$ e superóxido desmutase (SOD) como as principais enzimas ${ }^{(4)}$. 0 presente estudo analisou a atividade da catalase, que é uma enzima que faz a desmutação do $\mathrm{H}_{2} \mathrm{O}_{2}$, formado ao final da cadeia de transporte de elétrons, em $\mathrm{H}_{2} \mathrm{O}$ e $\mathrm{O}_{2}{ }^{(5)}$. Essa função é dividida com a glutationa peroxidase, a qual atua, preferencialmente, na presença de baixos níveis de $\mathrm{H}_{2} \mathrm{O}_{2}$, enquanto em altas concentrações de $\mathrm{H}_{2} \mathrm{O}_{2}$ predomina a ação da CAT ${ }^{(6)}$. A CAT é encontrada principalmente nos hepatócitos e eritrócitos, estando em grandes concentrações nos peroxissomas e em baixas concentrações nas mitocôndrias; também é encontrada maior atividade da catalase nos músculos com alta capacidade oxidativa(6,7). A escolha pela CAT se deu pelo fato de sua reação necessitar de alta concentração de $\mathrm{H}_{2} \mathrm{O}_{2}$, O que sugere forte evidência oxidativa.

Portanto, a dosagem dos níveis das atividades das enzimas antioxidantes e a quantificação de metabólitos de origem oxidativa podem servir para estimar o quadro de estresse oxidativo de diferentes sistemas celulares.

Segundo Schneider e Oliveira(2), as EROs são produzidas naturalmente em nosso organismo através de processos metabólicos oxidativos, sendo importantes em situações de necessidade de ativação do sistema imunológico. Por outro lado, a produção excessiva de EROs pode levar a situação de estresse oxidativo com subseqüentes efeitos prejudiciais ao organismo, tais como peroxidação lipídica, oxidação de proteínas, agressão a carboidratos e ao ácido desoxirribonucleico (DNA). Em relação ao desenvolvimento tumoral, as EROs também têm sido consideradas agentes causadores de danos ao DNA, que aumentam a taxa de mutação e promovem a transformação oncogênica ${ }^{(8)}$.

Em situação extrema no exercício físico malperiodizado, as EROs podem levar ao quadro conhecido como overreaching, que seria um distúrbio dos sistemas metabólicos e recuperativos ${ }^{(9)}$. A queda em atividade do sistema de defesa antioxidante só se torna preocupante se, após um período de recuperação, o organismo não restabelecer o equilíbrio redox. O overreaching pode ser facilmente revertido em poucos dias ou semanas; essa condição de queda na performance antecede um quadro muito mais grave e danoso ao organismo, o overtraining, que, além dos sintomas específicos de fadiga metabólica, induz severos distúrbios neuroendócrinos ${ }^{(10)}$. Alguns dos sintomas observados no overtraining incluem fadiga generalizada, depressão, apatia, dores musculares e articulares, infecções do trato respiratório superior e diminuição de apetite ${ }^{(11)}$.

Estudos sugerem que os sistemas antioxidante das células encontram-se alterados no câncer, causando um desequilíbrio no estado redox das mesmas. As células cancerosas estão continuamente sob estresse oxidativo persistente ${ }^{(12)}$. Toyokuni et al. ${ }^{(13)}$ acreditam que as próprias células cancerosas produzam EROs; porém, uma questão importante é se as células cancerosas produzem maior quantidade de EROs ou se o sistema antioxidante encontra-se suprimido.

Sabe-se que o exercício físico é uma conhecida forma de estresse ao organismo, sendo grande gerador de EROs. Por outro lado, o treinamento sistematizado é capaz de induzir adaptações positivas dos sistemas de defesa antioxidantes em resposta ao aumento da produção de EROs. O presente estudo tem como objetivo buscar valores de marcadores de estresse oxidativo e de alterações celulares tanto numa condição de overreaching induzido em animais submetidos a treinamento de natação quanto em animais inoculados com o tumor ascítico de Ehrlich (TAE). Tais dados poderão confrontar duas formas das mais severas de indução de estresse oxidativo, subsidiando futuras discussões da citotoxicidade do treinamento malperiodizado.

\section{MÉTODOS}

\section{Animais}

Os camundongos, machos, da linhagem Balb-C $(n=40)$, foram obtidos do Centro de Bioterismo da Unicamp, iniciando o processo de adaptação ao treinamento com quatro semanas de vida. Durante toda a execução dos protocolos, os camundongos foram mantidos em ambiente controlado, com temperatura variando entre 18 e $22^{\circ} \mathrm{C}$ e fotoperíodo invertido de 12 horas, estando providos de ração de laboratório e água ad libitum. Todos os animais foram mantidos no Biotério das Faculdades Integradas Metropolitanas de Campinas. Todos os experimentos foram realizados de acordo com protocolos institucionais aprovados pelo Comitê de Ética da Unicamp e das recomendações do Canadian Council on Animal Care.

Tabela 1. Características dos camundongos utilizados nos experimentos no momento de sacrifício

\begin{tabular}{l|c|c}
\hline & Peso (g) & Hemoglobina $(\mathbf{m g} / \mathbf{m L})$ \\
\hline Grupo CO $(n=10)$ & $28 \pm 1,2$ & $13,4 \pm 0,3$ \\
\hline Grupo T $(n=10)$ & $27 \pm 2,1^{*}$ & $15,1 \pm 0,6^{*}$ \\
\hline Grupo OVER $(n=10)$ & $23 \pm 1,2^{* *}$ & $11 \pm 0,6^{* *}$ \\
\hline Grupo TAE $(n=10)$ & $38 \pm 2,1^{*}$ & $9,3 \pm 0,4^{* *}$ \\
\hline
\end{tabular}

$\overline{\mathrm{CO}}=$ grupo controle; $\mathrm{T}$ = grupo treinamento periodizado; OVER = grupo submetido a overtraining; TAE = grupo inoculado com o tumor ascítico de Ehrlich. Considerando o parâmetro peso (g): ${ }^{*} p<0,05$ em relação ao grupo CO e TAE; ** $p<0,001$ em relação ao grupo CO, T e TAE; considerando o parâmetro hemoglobina $(\mathrm{mg} / \mathrm{mL}):{ }^{*} \mathrm{p}<0,05$ em relação ao grupo $\mathrm{CO}$; ${ }^{* *} \mathrm{p}<0,05 \mathrm{em}$ relação ao grupos $\mathrm{CO}, \mathrm{p}<0,01$ em relação ao grupo TAE; ${ }^{* * *} \mathrm{p}<0,001$ em relação ao grupo T e $p<0,01$ em relação aos grupos CO e OVER.

\section{Protocolo de treinamento e overreaching}

Os camundongos passaram por um período de adaptação ao treinamento de natação, com duração de uma semana (15 minutos de sessão de treino). Após o período de natação, os camundongos passaram a nadar cinco vezes por semana (segunda a sexta-feira), por um período de quatro semanas, com o tempo de sessão de treinamento elevando-se de 20 minutos até 60 minutos. Após esse período, um lote de camundongos foi 
sacrificado para análise desta fase sistematizada de treinamento (grupo T). Os animais sobreviventes foram submetidos a um ciclo de treinamento, o qual classificamos como fase de overreaching, consistindo de aumento progressivo semanal de uma sessão de treino, até chegar a quatro sessões de treino por dia, com duração de 60 minutos cada sessão.

\section{Inoculação com o tumor ascítico de Ehrlich}

O TAE caracteriza-se pela rápida atividade mitótica já na primeira semana após inoculação; a massa gerada tem crescimento contínuo e promove invasão de tecidos adjacentes; segundo Melo et al. ${ }^{(8)}, 90 \%$ das células do peritônio passam a ser tumorais após 10 dias de desenvolvimento. A linhagem tumoral de Ehrlich foi originalmente obtida de uma linhagem do Hospital do Câncer, São Paulo. Ela foi mantida no laboratório através de passagens sucessivas entre animais doadores. Suspensões de células tumorais $\left(6 \times 10^{7}\right.$ células viáveis $\left./ \mathrm{ml}\right)$ foram preparadas em solução salina balanceada com pH 7,4. As células tumorais de Ehrlich crescem como células ascíticas na cavidade peritoneal de camundongos, facilitando sua manutenção através de passagens consecutivas ${ }^{(8)}$. O número e a viabilidade das células tumorais (> 95\%) foram determinados em câmara de Neubauer, através da exclusão do corante azul de tripan. Animais portadores de TAE foram sacrificados no mesmo momento do grupo OVER.

\section{Preparação da amostra}

Após o animal ter sido anestesiado com hidrato de cloral (10\%) por via intraperitoneal, realizou-se uma secção abdominal, de forma que se pôde alcançar a veia hepática e coletar todo o sangue possível, que era depositado em tubos heparinizados. $O$ animal, após a extração de sangue, era sacrificado por deslocamento cervical. Plasma e hemácias eram obtidos após centrifugação do sangue total por 10 min a 3.000rpm. As amostras plasmáticas foram armazenadas para a realização das dosagens e determinações. As hemácias foram lavadas com solução gelada de tampão fosfato 0,1 M com $\mathrm{NaCl}$ a 0,9\%, pH 7,4, e centrifugadas a 3.000rpm, desprezando-se em seguida o sobrenadante. O processo foi repetido três vezes. Aliquotas de $500 \mu \mathrm{L}$ foram retiradas e hemolisadas com água destilada na proporção 1:1 (v/v), com posterior armazenamento a $-30^{\circ} \mathrm{C}$ para as seguintes análises: CAT e hemoglobina ( $\left.\mathrm{Hb}\right)$.

\section{Catalase}

A preparação da amostra iniciava-se com a adição de $900 \mu$ le tampão fosfato, pH 7.4, a 100 $\mu$ l do hemolisado (1:1), obtendo-se, assim, uma diluição 1:20 da amostra inicial. Deste hemolisado, $1 \mu$ l era adicionado ao meio básico de reação, que continha tampão fostato $50 \mathrm{~mm}, \mathrm{pH} 7,0$, e peróxido de hidrogênio $\left(\mathrm{H}_{2} \mathrm{O}_{2}\right) 10 \mathrm{mM}$. A medida da atividade da CAT ocorre através da velocidade com que o $\mathrm{H}_{2} \mathrm{O}_{2}$ é reduzido pela ação da enzima, provocando diminuição no valor da absorbância em 240nm. A diferença na leitura das absorvâncias a 240nm, em determinado intervalo de tempo (15 segundos), permite estabelecer a velocidade de redução do $\mathrm{H}_{2} \mathrm{O}_{2}$, que é proporcional à velocidade da reação enzimática catalisada pela $\mathrm{CAT}^{(14)}$ :

$$
2 \mathrm{H}_{2} \mathrm{O}_{2} \rightarrow 2 \mathrm{H}_{2} \mathrm{O}+\mathrm{O}_{2}
$$

O cálculo da atividade da CAT foi feito pela seguinte equação:

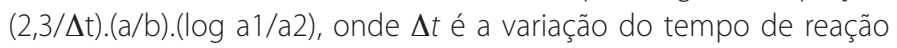
(15s), a é o volume de hemolisado na cubeta, $b$ é a concentração de hemoglobina da amostra em $\mathrm{g} / \mathrm{dL}$, a 1 é o valor da absorbância no tempo zero $(t=0)$ e a2 é o valor da absorbância no tempo final $(t=15 \mathrm{~s})$. A unidade final expressa-se em $\mathrm{k} / \mathrm{gHb} / \mathrm{min}$.

\section{Dosagem de hemoglobina no hemolisado}

A determinação da concentração de $\mathrm{Hb}$ no hemolisado torna-se fundamental para a obtenção dos valores finais de CAT. Os valores foram obtidos através do método de Drabkin ${ }^{(15)}$, em que a Hb $(100 \mu \mathrm{L}$ da amostra preparada a partir do hemolisado 1:20, descrito no método da CAT), em presença de reagente de Drabkin ( $2 \mathrm{~mL})$, forma um composto, a cianometaemoglobina, que é absorvida a 540nm e cujo coeficiente de extinção milimolar é 11,5 M-1.cm-1.

\section{Peroxidação lipídica}

Um dos métodos para quantificação dos produtos da peroxidação lipídica é o de análise da formação de substâncias que reagem ao ácido tiobarbitúrico (TBARS). Esse método consiste na análise dos produtos finais da peroxidação lipídica (peróxidos lipídicos, malondialdeídos e demais aldeídos de baixo peso molecular) que, ao reagir com o ácido 2-tiobarbitúrico (TBA), formam bases de Schiff. Tais complexos são coloridos e sua concentração pode ser determinada espectrofotometricamente a $535 \mathrm{~nm}$, ou por fluorescência a 515nm de excitação e $555 \mathrm{~nm}$ de emissão(16).

As amostras foram preparadas de acordo com Yagi(16), onde $20 \mu \mathrm{L}$ de plasma eram diluídos em $4 \mathrm{~mL}$ de $\mathrm{H}_{2} \mathrm{SO}_{4}(0,04 \mathrm{M})$. Adicionava-se a essa diluição 0,5mL de ácido fosfotúngstico a 10\% e aguardavam-se cinco minutos para a centrifugação a 3.000rpm por 10 min. O sobrenadante era descartado e suspendia-se o precipitado em $2 \mathrm{~mL} \mathrm{de} \mathrm{H}_{2} \mathrm{SO}_{4}(0,04 \mathrm{~mL})$, seguindo a adição de 0,3mL de ácido fosfotúngstico a 10\%. Após centrifugação a 3.000rpm por 10 min, descartava-se novamente o sobrenadante e dissolvia-se o precipitado em $0,5 \mathrm{~mL}$ de $\mathrm{H}_{2} \mathrm{O}$ deionizada. Adicionavase a essa mistura $1 \mathrm{~mL}$ da solução composta de ácido tiobarbitúrico a 0,67\% em ácido acético a 50\%. A amostra era incubada em banho-maria a $95^{\circ} \mathrm{C}$ por uma hora. Após o resfriamento, foi efetuada a extração das substâncias reativas ao ácido tiobarbitúrico (TBARS) com $5 \mathrm{~mL}$ de butanol. As análises foram feitas por espectrofotometria $(535 \mathrm{~nm})$ e o cálculo da concentração de TBARS, por meio de uma curva-padrão de tetraetoxipropano; os resultados foram expressos em $\mathrm{nmol} / \mathrm{mL}$ de plasma.

\section{Creatina quinase}

A concentração de CK no sangue reflete índices de lesão muscular. A dosagem desse parâmetro foi realizada espectrofotometricamente por método cinético - UV (Laborlab, CK-NAC, CAT N.․06100), através de $20 \mu \mathrm{L}$ de plasma misturado com a solução reagente. A mistura foi incubada em banho-maria por um minuto a $37^{\circ} \mathrm{C}$, sendo feita a leitura das absorvâncias em 340nm de acordo com as normas do kit. A unidade final foi expressa em U/L.

\section{Creatinina e uréia}

O teste de creatinina é feito para determinar o produto final do catabolismo muscular, enquanto que o de uréia permite estabelecer o produto final do metabolismo purínico. Para a realização dos dois marcadores, utilizaram-se o método cinético ou direto sem desproteinização (creatinina, Laborlab ', CAT N.. 01600, leitura a 510nm) e o método enzimático (ácido úrico, Laborlab , CAT N. 00100, leitura a 530nm) em amostras de plasma. Os valores foram calculados de acordo com as normas do fabricante, com unidade final expressa em $\mathrm{mg} / \mathrm{dL}$.

\section{Análises estatísticas}

As análises estatísticas foram feitas através do programa GraphPad Instat ${ }^{\oplus}$ (San Diego, CA, EUA). Utilizamos o teste ANOVA para amostras pareadas e, como pós-teste, foi adotado o teste de Tukey. Valores de $P$ $<0,05$ foram considerados significativos.

\section{RESULTADOS}

\section{Marcadores de estresse oxidativo}

A figura 1-A apresenta os valores da atividade da enzima antioxidante catalase mais significativos ( $p<0,001)$ para o grupo $T$ em relação, sobretudo, aos valores controle (CO), porém mantendo-se elevados comparados com os grupos OVER $(p<0,01)$ e TAE $(p<0,05)$. 
O grupo OVER manteve-se com valores elevados significativos, ainda, em comparação com o grupo CO ( $p<0,01)$ e TAE $(p<0,05)$. Um dado importante foi observar que a atividade antioxidante de CAT decresceu significativamente em relação ao grupo $C O(p<0,05)$ e aos grupos submetidos ao treinamento $(T)$, $(p<0,001)$, e ao overreaching $(p<0,01)$. A Figura 1-B apresenta valores crescentes significativos em formação de TBARS quando se compara o grupo CO com o grupo T $(p<0,05)$, com o grupo OVER $(p<0,01)$ e com o grupo TAE $(p<0,001)$.

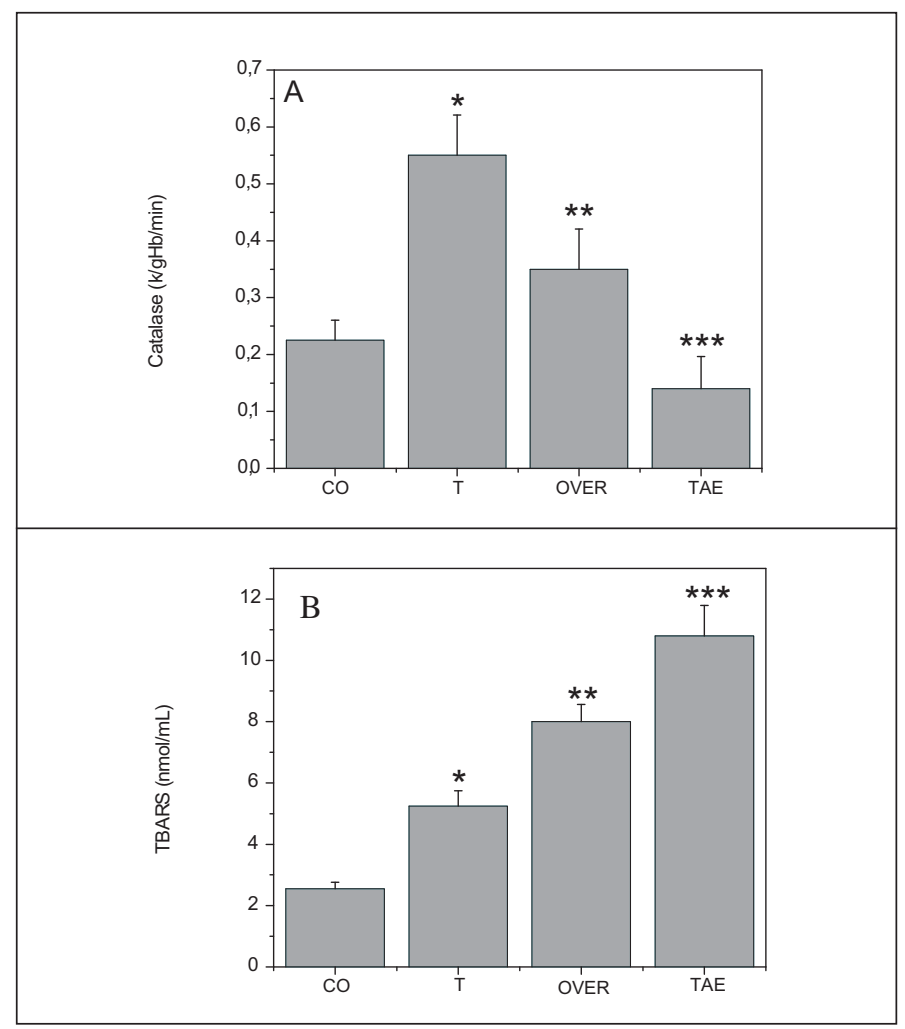

Figura 1. A) Atividade da enzima catalase nos eritrócitos e B) concentrações de TBARS no plasma em animais controle (CO), submetidos a protocolos de treinamento de natação $(T)$, condição de overreaching (OVER) e inoculados com tumor ascítico de Ehrlich sem treinamento (TAE) ( $n=10$ cada grupo). $\mathbf{A}) * p<0,001$ em relação aos grupos $\mathrm{CO}$ e TAE, $p<0,01$ em relação ao grupo $T_{;} *{ }^{*} p<0,01$ em relação aos grupos $\mathrm{CO}$ eTAE; ${ }^{* * *} p<0,05$ em relação ao grupo $\left.\mathrm{CO} ; \mathbf{B}\right){ }^{*} p<0,05$ em relação ao grupo $\mathrm{CO}$; ${ }^{* *} p<0,01$ em relação ao grupo $C O$ e $p<0,05$ em relação ao grupo $T$; *** $p<0,001$ em relação ao grupo $C O$ e T, $p<0,01$ em relação ao grupo OVER.

\section{Marcadores de lesões celulares}

A figura 2-A apresenta a concentração de creatina quinase com níveis estatísticos significativos ao comparar o grupo T com o CO $(p<0,05)$, com elevação crescente em relação ao grupo T e OVER $(p<0,001)$. Uma queda significativa é vista ao analisar o grupo TAE em relação ao grupo OVER ( $p<0,001)$, porém, mantendo-se elevado em comparação com os grupos CO e T $(p<0,05)$. A Figura 2-B apresenta um padrão de elevação mais específico para o parâmetro da enzima aspartato transaminase, pois há elevação significativa apenas em comparação dos grupos OVER e TAE com os grupos CO e T $(p<0,01)$.

\section{Marcadores de alterações fisiológicas}

A figura 3-A apresenta valores de creatinina significativamente elevados do grupo T em relação ao grupo $C O(p<0,01)$, com elevação crescente do grupo OVER em relação ao grupo T $(p<0,01)$ e aos grupos CO e TAE $(p<0,001)$. Há queda significativa $(p<0,05)$ do grupo TAE em relação ao grupo CO. A Figura 3-B mostra que, para as análises de uréia, houve aumento significativo moderado $(p<0,05)$ dos grupos Te OVER em relação ao grupo CO e aumento extremamente significativo do grupo TAE em relação aos grupos CO, T e OVER $(p<0,001)$.
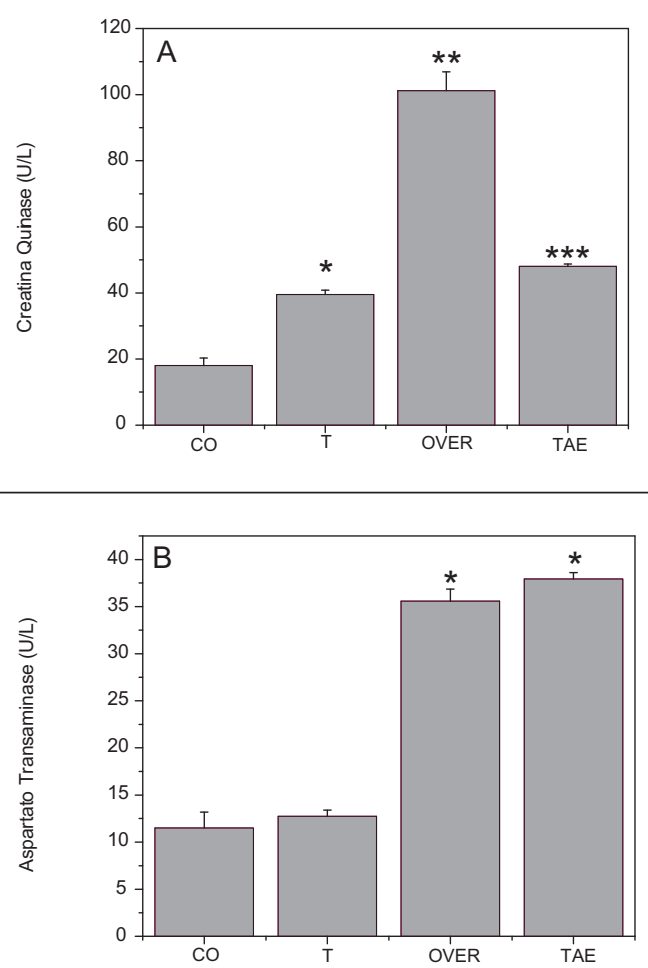

Figura 2. Concentrações plasmáticas de creatina quinase $(\mathbf{A})$ e aspartato transaminase (B) em animais controle (CO), submetidos a protocolos de treinamento de natação (T), condição de overreaching (OVER) e inoculados com tumor ascítico de Ehrlich sem treinamento (TAE) ( $n=10$ cada grupo). $\mathbf{A}){ }^{*} p<0,05$ em relação ao grupo $C O$; ** $p<0,001$ em relação aos grupos $\mathrm{CO}, \mathrm{Te} \mathrm{TAE}^{* * *} \mathrm{p}<0,05$ em relação ao grupo CO; B) ${ }^{*} p<0,001$ em relação aos grupos CO e $T$.
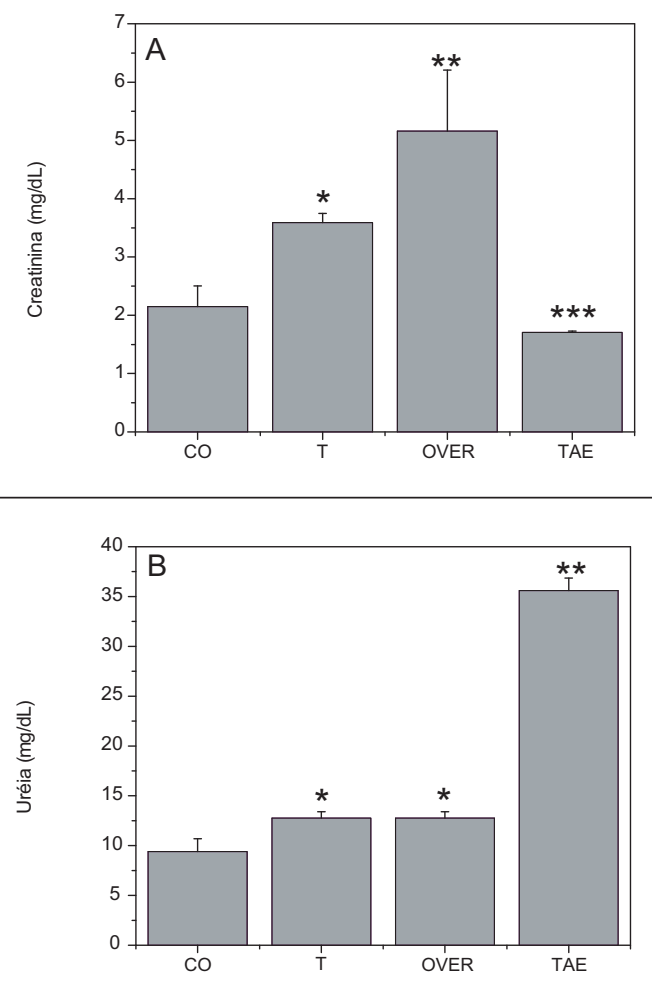

Figura 3. Concentrações plasmáticas de creatinina (A) e uréia (B) em animais controle (C), submetidos a protocolos de treinamento de natação (T), condição de overreaching (OVER) e inoculados com tumor ascítico de Ehrlich sem treinamento (TAE) $(n=10$ cada grupo). (A) * $p<0,01$ em relação ao grupo $C O ;{ }^{* *} p<0,001$ em relação aos grupos $\mathrm{CO}$ e TAE e $p<0,01$ em relação ao grupo T; *** $p<0,05$ em relação ao grupo $\mathrm{CO}$; $(\mathbf{B}){ }^{*} p<0,05$ em relação aos grupos T e OVER e ** $p<0,001$ em relação aos grupos CO, T e OVER. 


\section{DISCUSSÃO}

A quantificação dos níveis de estresse oxidativo permite o monitoramento do estado de treinamento do atleta, dando margens para a modulação das cargas de treino. Como mostrado por Antunes Neto et al.(9), as respostas moleculares precedem as respostas fisiológicas na instalação de um quadro de estresse oxidativo, podendo dar indícios do efeito do treinamento sobre o organismo do atleta.

Os dados apresentados em nosso estudo mostram que existe elevação na peroxidação lipídica (TBARS) (figura 1-B) em todos os grupos estudados (T, OVER e TAE) quando comparados com o grupo CO. Contudo, também se observa que a atividade antioxidante (figura 1-A), medida através da enzima CAT, mediante treinamento sistematizado e devidamente controlado, é capaz de modular tal parâmetro ao novo estado redox das células e combater os efeitos deletérios causados pelas EROs, tendo a possibilidade de reverter um possível quadro de instalação de estresse oxidativo. Por outro lado, treinamento mal-estruturado, sem períodos de recuperação adequados, como o desenvolvido no grupo OVER, pode aumentar a ação das EROs, fazendo com que o sistema de defesa antioxidante não consiga modular-se a esse processo oxidativo, de maneira que se pode observar aumento na quantidade de TBARS e, concomitante, queda nos valores da atividade de CAT (figura 1), caracterizando, assim, uma situação de estresse oxidativo. Vale ressaltar que os valores comparativos para o grupo OVER devem ser feitos com os dados obtidos pelo grupo T, pois apenas há situação de overreaching em organismos que se encontram em uma estrutura de treinamento. Dessa forma, considera-se significativa a queda em atividade de CAT, para o grupo OVER, em comparação com o grupo T, mesmo sendo aquela mais elevada ao confrontar com os valores do grupo CO. O aumento em peroxidação lipídica, para o grupo OVER, corrobora a idéia de que os níveis enzimáticos de CAT (apesar do aumento comparativo com o grupo CO) não são suficientes para impedir o aumento da concentração dos hidroperóxidos.

O mesmo quadro pode ser observado no grupo TAE, onde o aumento da peroxidação lipídica foi altamente significativo em relação ao CO e $T(p<0,001)$ e significativamente maior ( $p<0,01)$ em relação ao OVER, a atividade de CAT mostrando-se reduzida quando comparada com a dos demais grupos. Tais dados sugerem que a situação patológica induzida pelo TAE provoca maior citotoxicidade celular. O TAE, um carcinoma de crescimento rápido, de alto poder necrótico e comportamento muito agressivo, caracteriza-se por alterações profundas na resposta imunitária, resultando na disfunção de células T e NKs, responsáveis pela vigilância imunitária e recrutamento de macrófagos ${ }^{(17,18)}$. Considerando que níveis de estresse oxidativo induzidos pelo exercício podem atingir um mesmo perfil ao comparar-se com uma situação patológica, os dados obtidos neste estudo são extremamente reveladores sobre a importância de implementação de períodos recuperativos adequados para a instalação dos eventos supercompensatórios.

\section{REFERÊNCIAS BIBLIOGRÁFICAS}

1. Antunes Neto JMF, Toyama MH, Carneiro EM, Boschero AC, Pereira-da-Silva L, Macedo DV. Circulating leukocyte heat shock protein 70(HSP70) and oxidative stress markers in rats after a bout of exhaustive exercise. Stress 2006;9:107-15.

2. Schneider CDE, Oliveira AR. Radicais livres de oxigênio e exercício: mecanismos de formação e adaptação ao treinamento físico. Rev Bras Med Esporte 2004;10:87-90.

3. Antunes Neto JMF, Pereira-da-Silva L, Macedo DV. Biomarcadores de estresse oxidativo: novas possibilidades de monitoramento em treinamento físico. Rev Bras Cien Mov 2005;13:73-80.

4. Powers SK, Criswell D, Lawler J, Ji LL, Martin D, Herb RA. et al. Influence of exercise and fiber type on antioxidant enzyme activity in rat skeletal muscle. Am J Physiol 1994;266:R-375-80.

5. Yu BP. Cellular defenses against damage from reactive oxygen species. Physiol Rev 1994;74:139-62.

6. Barreiros ALB, David JM. Estresse oxidativo: relação entre geração de espécies reativas e defesa do organismo. Quim Nova 2006;29:113-23.

7. Halliwell B, Gutteridge JM. Free radicals in biology and medicine. Oxford: Clarendon Press, 1989.

8. Melo PS, Antunes Neto JMF, Duran N, Haun M. Efeito anti-tumoral da desidrocrotonina: modulação do estresse oxidativo em animais portadores do tumor ascítico de Ehrlich. Rev Soc Brasileiras Câncer 2007;14:12-21.

9. Zoppi CC, Hohl R, Silva FOC, Lazarim FL, Antunes Neto JMF, Stancanelli M, et al. Vitamin C and E supplementation effects in professional soccer players under regular training. J Int Soc Sports Nutr 2006;3:37-44.

10. Tiidus PM. Radical species in inflammation and overtraining. Can J Physiol Pharmacol 1998;76:533-8.
Dados da literatura sugerem que o processo oxidativo gerado pelo exercício físico contribui com os eventos de lesão celular ${ }^{(1,19,20)}$. Em nosso estudo, observou-se aumento significativo nos valores de extravazamento de creatina quinase-CK (indicador de lesão muscular) em todos os grupos quando comparados com os valores CO (figura 2), coincidindo com o aumento de peroxidação lipídica nesses mesmos grupos. Aumento na permeabilidade da membrana, em virtude da peroxidação lipídica, pode ter contribuído com a liberação de $\mathrm{CK}^{(1)}$. Entretanto, observou-se queda nos valores da CK plasmática do grupo TAE em comparação com o grupo OVER. Equipes técnicas esportivas devem refletir em tal condição, uma vez que valores mais elevados de CK plasmático foram encontrados em animais sujeitos ao overreaching em comparação com animais de um grupo patológico severo (TAE). Esse dado reforça a importância da utilização dos níveis plasmáticos de CK como indicador de alteração celular.

Com relação aos marcadores fisiológicos, observou-se aumento significativo da creatinina nos grupos T e OVER em relação aos grupos $\mathrm{CO}$ e TAE (figura 3-A), indicando que o treinamento aumenta a degradação das bases purínicas. Os valores da uréia foram significativos em T e OVER em relação ao CO e extremamente significativos em TAE em relação a OVER, T e CO, demonstrando uma condição de catabolismo protéico nesses grupos. O maior valor de uréia no grupo TAE pode advir de provável processo oxidativo sobre as proteínas estruturais e de deficiência do turnover protéico, uma vez que o processo de ressíntese dos aminoácidos é feito no fígado, e tal órgão poderia se encontrar em deficiência pela ação carcinogênica. Esta condição poderia explicar os valores aumentados da AST, que é uma enzima com grande concentração neste órgão (figura 2-B).

Concluindo, nossos dados sugerem fortemente que as técnicas moleculares de detecção da situação de estresse oxidativo (CAT eTBARS), em conjunto com a análise de marcador de lesão tecidual (CK), são ferramentas precisas e que podem colaborar com a prescrição do treinamento físico, mas, sobretudo, predizer quadros lesivos de ordem mais aguda. Outro ponto a ser ressaltado é que as dosagens sangüíneas indicam com alta sensibilidade as alterações que ocorrem nos sistemas orgânicos como um todo, podendo substituir técnicas mais invasivas, como as biópsias, que são de difícil permissão e acesso em nosso país e que sempre encontram resistência por parte de atletas e comissão técnica. Por fim, fica fortemente evidenciado que o descontrole das cargas de treinamento pode levar o organismo a níveis de estresse oxidativo que se confundem com uma situação patológica. A busca de respostas adaptativas positivas pode percorrer limiares altamente desafiadores, onde a diferença podem ser as metodologias de controle do treinamento.

\section{FOMENTO}

ProMetro - Programa de Qualidade e Responsabilidade Social da Metrocamp.

Todos os autores declararam não haver qualquer potencial conflito de interesses referente a este artigo.

11. Rogero MM, Mendes RRE, Tirapegui J. Aspectos neuroendócrinos e nutricionais em atletas com overtraining. Arq Bras Endocrinol Metab 2005;49:110-3.

12. Brown NS, Bicknell R. Hypoxia and oxidative stress in breast cancer oxidative stress: its effects on the growth, metastatic potential and response to therapy of breast cancer. Breast Cancer Res 2001;3:323-7.

13. Toyokuni S, Okamoto K, Yodoi J, Hiai H. Persistent oxidative stress in cancer. FEBS Lett 1994;358:10-3.

14. Aebi H. Catalase. In: Methods in Enzymology. Packer L, editor. Florida: Academic Press, 1984;105:121-6.

15. Beutler E. Red cell metabolism. In: A Manual of Biochemical Methods. London: Grune \& Stratton Publishers, 1975.

16. Yagi K. Lipid peroxides and human diseases. Chemi Phys Lipids 1987;45:337-51.

17. Freire ACG, Melo PS, Haun M, Durán N, Aoyama H, Ferreira CV. Cytotoxicity of lactone from Croton cajucara in human leukaemic cells. Planta Med 2003;69:67-9.

18. Hristov PK, Petrov LA, Russanov EM. Lipid peroxidation induced by ultrasonication in Ehrlich ascitic tumor cells. Cancer Lett 1997;121:7-10.

19. Armstrong RB. Mechanisms of exercise-induced delayed onset muscular soreness: a brief review. Med Sci Sports Exerc 1984;16:529-38.

20. Duarte JA, Carvalho F, Bastos L. Do invading leucocytes contribute to the decrease in glutathione concentrations indicating oxidative stress in exercised muscle, or are they important for its recovery? Eur J Appl Physiol 1994;68:48-53. 